\title{
Note
}

\section{Influence of Interfacial Layer Growth on the Kinetics of Iron Enrichment in Hot-dip Galvan- neal Coatings on IF Steel Sheets}

\section{Introduction}

A simple model ${ }^{1,2)}$ has been recently proposed to describe the isothermal kinetics of coating iron enrichment of hot-dip galvanized interstitial free (IF) steels during isothermal galvannealing. Jordan et al., ${ }^{3)}$ Lin et $a l^{4)}$ and Xavier et $a l .^{5)}$ data were found to agree well with the model. The model has been extended to account for the effect of the coating weight on the isothermal kinetics. ${ }^{6)}$ It has also been shown that isothermal kinetics data described by the model can be successfully used to predict non-isothermal iron enrichment kinetics. ${ }^{1,7)}$

The basic assumption in the model is that the rate of increase in the coating iron content, $d W / d t$, is proportional to the difference between a certain saturation coating iron content (in mass $\%$ ), $W_{\mathrm{S}}$, and the coating iron content, $W$, (also in mass $\%$ ). The integrated equation is:

$$
W=W_{0}+\left(W_{\mathrm{s}}-W_{0}\right)(1-\exp (-k t))
$$

where $W_{0}$ is the coating iron content for $t=0$.

Equation (1) was proposed to describe the kinetics of iron enrichment up to the end of stage II of the galvannealing process. $^{1-3)}$ The end of stage II occurs when the interfacial layer growth ( $\Gamma$ and/or $\Gamma_{1}$ phases) begins to dominate the iron enrichment kinetics. At this point the coating is normally constituted by iron saturated $\delta$ phase separated from the iron substrate by an interfacial layer. So while Eq. (1) predicts a certain saturation iron content, $W_{\mathrm{s}}$, the iron content of the coating will increase beyond this value due to the growth of the interfacial layer. It can be clearly seen in previous works ${ }^{1,2,5,7)}$ that the measured coating iron content deviates upwards from the model beyond a coating iron content roughly equal to 13 mass $\%$.

In this work a detailed study of the interfacial layer growth is carried out and its contribution to the overall iron enrichment is discussed.

A hot-dip galvanized interstitial free (IF) steel sheet with coating weight of $81 \mathrm{~g} / \mathrm{m}^{2}$ on one side and $76.5 \mathrm{~g} / \mathrm{m}^{2}$ on the other was used. For the present work only results from the side with $81 \mathrm{~g} / \mathrm{m}^{2}$ were used. The chemical composition of the substrate was (in mass\%): $\mathrm{C}-0.0035$; $\mathrm{Mn}-0.143 ; \mathrm{P}-0.0125 ; \mathrm{S}-0.0074 ; \mathrm{Si}-0.0055$; Ti-0.0725; $\mathrm{N}-0.0026 ; \mathrm{Al}-0.0467$; Fe-balance. Specimens measuring $100 \times 100 \times 0.85 \mathrm{~mm}$ were annealed in salt bath at 450 , 500 , and $550^{\circ} \mathrm{C}$ for holding times ranging from $5-120 \mathrm{~s}$ and water quenched (cooling rate about $90^{\circ} \mathrm{C} / \mathrm{s}$ ). The heating rate was about $40^{\circ} \mathrm{C} / \mathrm{s}$ and the annealing times were measured from the instant the specimen reached the required temperature. From the center of the specimens disks with $60 \mathrm{~mm}$ in diameter were taken for the determination of iron content. This was done separately on each side of the disk using a sulfuric acid solution to dissolve the coating. The Al content of the zinc bath was high, 0.21 mass $\%$ (nominal), so the amount of iron initially present in the coating was very low. Optical microscopy of the as galvanized sheet revealed that the coating was entirely $\eta$ phase, almost pure zinc. The interfacial layer thickness was measured by a scanning electron microscope using backscattered electrons.

The interfacial layer thickness is plotted as a function of annealing time in Fig. 1. As expected, the growth kinetics is faster for higher annealing temperatures. An interesting point of the present result is that the interfacial layer grows continuously as a function of time. This differs from Jordan et al. ${ }^{3)}$ who found that in their case the interfacial layer thickness remained approximately constant until the end of stage II, when iron content reached a value roughly around 12 mass $\%$ (see Fig. 8 of Jordan et $a{ }^{3}{ }^{3)}$ ). This discrepancy can be explained by the fact that in their case the $\mathrm{Al}$ content of the $\mathrm{Zn}$ bath was significantly lower than the present case, about $0.10 \mathrm{mass} \%$, so that they could not avoid having an initial coating iron content of 3 mass $\%$. This initial high iron content apparently led to a fast formation of a $1 \mu \mathrm{m}$ thick interfacial layer. Jordan et $a l^{3)}$ called this the stage I. In the present case the high $\mathrm{Al}$ content of the $\mathrm{Zn}$ bath prevented this. The initial coating iron content was virtually nil and no rapid initial growth of the interfacial layer was found, thus, no stage I. The important point is perhaps not whether the interfacial layer grows slowly or fast but how much of the iron enrichment is due to its growth. To make this point more clear one can divide the total coating iron content, $W$, in two parts: "interfacial layer", $W_{\mathrm{l}}$, and the "zinc layer", $W_{\mathrm{Zn}}$, iron

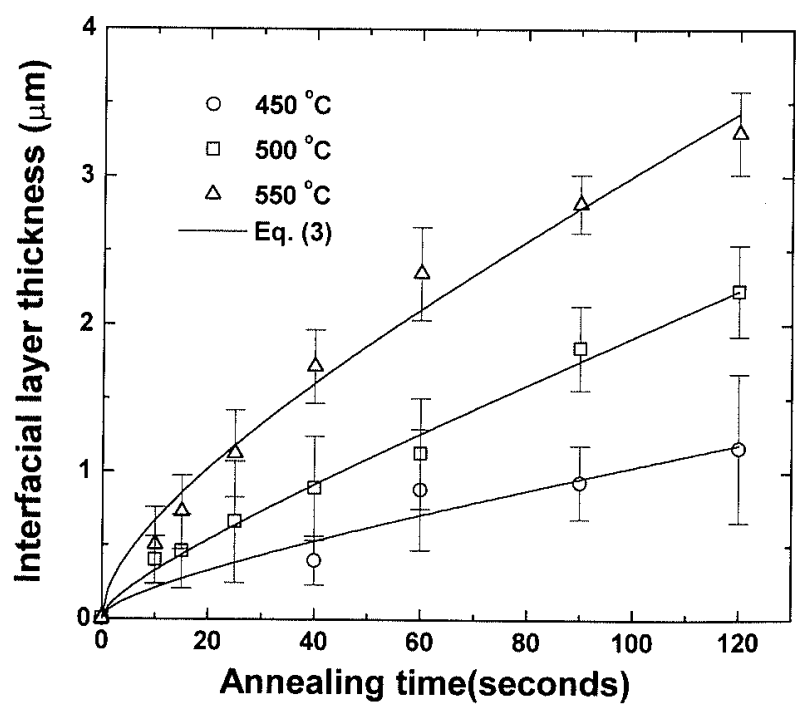

Fig. 1. Interfacial layer thickness $(\mu \mathrm{m})$ as a function of isothermal annealing hold time (sec). Good agreement is observed between Eq. (3) and experimental data. 
content. So the increase in total coating iron content $d W$ can be written as:

$$
d W=d W_{\mathrm{Zn}}+d W_{\mathrm{I}}
$$

where $d W_{Z_{n}}$ is the contribution of the iron that goes into the $\mathrm{Zn}$ layer to form zeta or delta phases and $d W_{\mathrm{I}}$ is the contribution of the iron that goes into the interfacial layer ( $\Gamma$ and/or $\Gamma_{1}$ phases). One can then define two growth regimes: initially $d W_{\mathrm{Zn}_{\mathrm{n}}} \gg d W_{\mathrm{I}}$ and later $d W_{\mathrm{Zn}} \ll$ $d W_{\mathrm{I}}$. Initially the iron enrichment is dominated by the increase in iron content of the $\mathrm{Zn}$ layer itself and later when this layer is fully alloyed the iron enrichment is dominated by the growth of the interfacial layer. On deriving Eq. (1) the term $d W_{1}$ was neglected. Therefore Eq. (1) is a good approximation for $d W_{z_{n}} \gg d W_{1}$ but becomes an increasingly worse approximation as $d W_{\mathrm{I}}$ becomes comparable and eventually larger than $d W_{\mathrm{Zn}}$.

In order to derive a model for the whole range of iron content it is necessary to introduce the term $d W_{1}$. This can be done first by noticing that the curves of Fig. 1 can be fitted by a simple expression of the form:

$$
X=X_{0}+C t^{n}
$$

where $X_{0}$ is the initial thickness of the interfacial layer, taken as zero in the present case; $C$ and $n$ are adjustable parameters. Nonlinear curve fitting was used for fitting data given in Fig. 1 to Eq. (3). it can be seen that the agreement is good.

In order to convert thickness to mass $\%$ one can multiply Eq. (3) by an appropriate factor:

$$
W_{\mathrm{I}}=W_{01}+C_{\mathrm{I}} t^{n}
$$

where $W_{0 \mathrm{I}}$ is the part of the initial iron content that is located in the interfacial layer and $C_{\mathbf{I}}$ is an adjustable parameter.

One can then combine Eqs. (1) and (4) resulting in:

$$
W=W_{\mathrm{oZn}}+\left(W_{\mathrm{SZn}}-W_{\mathrm{oZn}}\right)(1-\exp (-k t))+W_{0 \mathbf{I}}+C_{\mathrm{I}} t^{n}
$$

where $W_{0}=W_{0 \mathrm{Zn}}+W_{0 \mathrm{I}}$ is the initial coating iron content, $W_{0 \mathrm{Zn}}$ is the part of the initial iron content that is located at the zinc layer. $W_{\mathrm{Szn}}$ will in general different from $W_{\mathrm{S}}$ obtained from Eq. (1).

In the present case $W_{0}$ can be taken as zero so Eq. (5) simplifies to:

$$
W=W_{\mathrm{SZn}}(1-\exp (-k t))+C_{1} t^{n}
$$

Coating iron content against annealing hold time is plotted Fig. 2. One can assess the effect of the growth of the interfacial layer on the kinetics of iron enrichment by fitting Eqs. (1) and (6) to the data of Fig. 2.

For the purpose of fitting Eq. (1) data points that are indicated by arrows in Fig. 2 were excluded from the fitting. Equation (1) is represented by the dashed lines.

Fitting of Eq. (6) was carried out using the value of $n$ found by fitting Eq. (3) to data of Fig. 1 and the value of $k$ obtained by fitting Eq. (1) to data of Fig. 2. Only $W_{\mathrm{SZn}}$ and $C_{\mathrm{I}}$ were adjusted. A summary of fitted parameters can be found in Table 1 . Notice that $W_{\mathrm{SZn}}$ remains reasonably close to $W_{\mathrm{S}}$. It can be seen from Fig. 2 that Eq. (6), represented by the solid lines, is able to describe

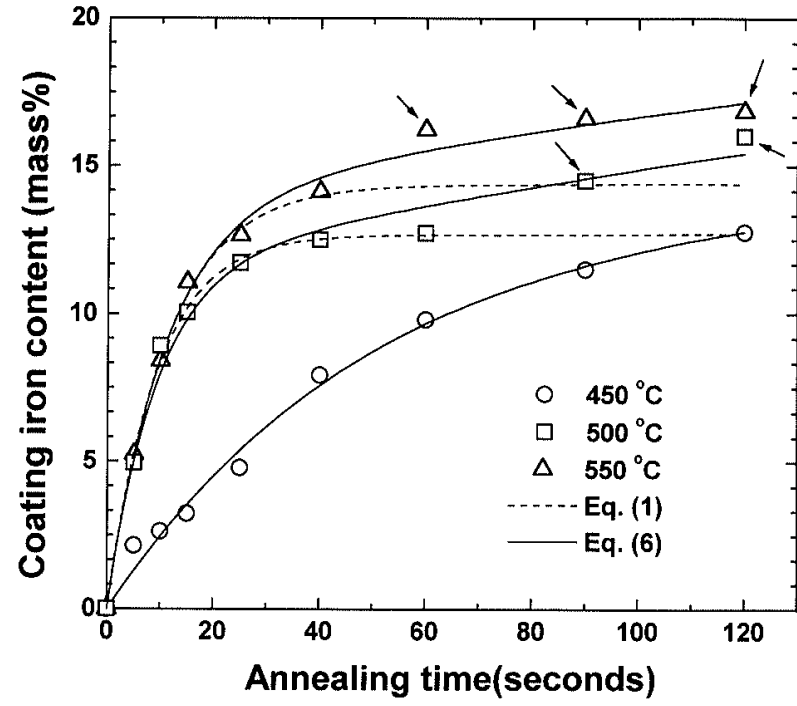

Fig. 2. Isothermal iron enrichment kinetics. Dashed and solid lines were obtained by fitting Eqs. (1) and (6) to the

\begin{tabular}{|c|c|c|c|c|c|c|}
\hline \multirow[b]{2}{*}{$T\left({ }^{\circ} \mathrm{C}\right)$} & \multicolumn{2}{|c|}{ Eq. (1) } & \multicolumn{2}{|c|}{ Eq. (3) } & \multicolumn{2}{|c|}{ Eq. (6) } \\
\hline & $\begin{array}{c}W_{\mathrm{s}} \\
(\mathrm{mass} \%)\end{array}$ & $\begin{array}{c}k \\
\left(s^{-1}\right)\end{array}$ & C & $n$ & $\begin{array}{c}W_{\mathrm{sZn}} \\
(\mathrm{mass} \%)\end{array}$ & $C_{\mathrm{I}}$ \\
\hline 450 & 14.2 & 0.019 & 0.013 & 0.95 & 14.2 & 0 \\
\hline 500 & 12.8 & 0.108 & 0.061 & 0.75 & 11.1 & 0.12 \\
\hline 550 & 14.4 & 0.090 & 0.128 & 0.69 & 13.1 & 0.15 \\
\hline
\end{tabular}
experimental data, respectively. The arrows indicate points which were not included when fitting with $\mathrm{Eq}$ (1).

Table 1. Summary of fitted parameters.

well the coating iron content over the whole iron content range. At $450^{\circ} \mathrm{C}$ both curves coincided and $C_{\mathrm{I}}$ was equal to zero. This happened because at this tempeature for the iron contents studied the contribution of the interfacial layer was very small.

Comparing Eqs. (1) and (6) it is clear that the solid and dashed curves are very close up to iron contents roughly about 13 mass $\%$. This is close to the value of 12 mass \% found by Jordan et al. ${ }^{3)}$ to be the value for which growth of the interfacial layer became important.

The above analysis allows one to conclude that Eq. (1) is a good description of the kinetics up to an iron content roughly about 13 mass \%. Beyond this one has to consider the contribution of the interfacial layer growth which is done in Eq. (6). In practice however one is mainly interested in coating iron contents below 13 mass $\%$ as powdering properties become significantly worse as the iron content is increased above 10 mass $\%$. As a consequence, Eq. (1) is probably satisfactory for most practical purposes.

In conclusion the contribution of the interfacial layer to the coating iron content can be neglected for coating iron contents below roughly about 13 mass $\%$. Beyond this the contribution of the growth of the interfacial layer has to be taken into account. When this is done, Eq. (6) reaches good agreement over the whole iron content range. 


\section{Acknowledgments}

This work was supported by Companhia Siderúrgica Nacional (CSN) through an agreement with Universidade Federal Fluminense (UFF). U. R. Seixas is grateful to CSN for the scholarship and for granting the leave to work at UFF. P. R. Rios is also grateful to Conselho Nacional de Desenvolvimento Científico e Tecnológico (CNPq) for the financial support.

\section{REFERENCES}

1) P. R. Rios: Metall. Mater. Trans. A, 27A (1996), Il32.

2) P. R. Rios: ISIJ Int., 36 (1996), 361.

3) C. E. Jordan, K. M. Goggins and A. R. Marder: Metall. Mater. Trans. A, 25A (1994), 2101.

4) C. S. Lin, M. Meshii and C. C. Cheng: ISIJ Int, 35 (1995), 503.

5) C. R. Xavier, U. R. Seixas and P. R. Rios: ISIJ Int., 36 (1996), 1316.
6) C. R. Xavier, U. R. Seixas and P. R. Rios: J. Mater. Eng. Perf., 6 (1997), 596

7) U. R. Seixas and P. R. Rios: ISIJ Int., 37 (1997), 1040.

(Received on July 23, 1997; accepted in final form on September 8, 1997)

U. R. SEIXAS and P. R. RIOS ${ }^{11}$

Companhia Siderúrgica Nacional, Centro de Pesquisa e Desenvolvimento, Rua 4, 33, Conforto, Volta Redonda, RJ, 27269-900 Brasil.

1) Universidade Federal Fluminense, Escola de Engenharia Industrial Metalúrgica de Volta Redonda, Av. dos Trabalhadores, 420 , Vila Snata Cecília, Volta Redonda, RJ, 27260-740 Brasil. 